\title{
INTRODUCING BACKSTAGE - A DIGITAL BACKCHANNEL FOR LARGE CLASS LECTURES
}

\author{
Alexander Pohl*, Vera Gehlen-Baum^, François Bry* \\ * Institute for Informatics, University of Munich \\ Oettingenstraße 67, 80538 München, Germany \\ http://pms.ifi.lmu.de \\ - Department of Educational Technology, Saarland University \\ Campus C5 4, 66123 Saarbrücken, Germany \\ http://edutech.uni-saarland.de
}

\begin{abstract}
ABS TRACT
This article reports on the conception of a novel digital backchannel, project name Backstage, dedicated to large classes aiming at empowering not only the audience but also the speaker, at promoting the awareness of both audience and speaker, and at promoting an active participation of students in the lecture. The backchannel supports different forms of inter-student communication via short microblog messages, social evaluation and ranking of messages by the students themselves. Backstage allows for the aggregation of student's opinions aiming at supporting the community building of the audience and strengthening the students' awareness of and co-responsibility for the class work. The backchannel further supports immediate concise feedback to the lecturer of selected and aggregated students' opinions making it possible to strengthen the lecturer's awareness for students' difficulties. The backchannel's conception is motivated by learning sciences' findings and theories.
\end{abstract}

This article is an extended version of (Bry et al., 2011) published at the IADIS International Conference e-Society, held in March 2011 in Avila, Spain.

\section{KEYWORDS}

E-Learning, Social Media, Enhanced Classroom, Digital B ackchannel

\section{INTRODUCTION}

Fifty years ago, European higher education opened up to a much larger part of the society, turning popular courses of study to mass education and universities to degree factories (Hartmann, 2007): Class lectures with several hundred students has become daily life in European academia. In such classes, both a lecturer's awareness and the students' participation in the lecture tend to dramatically decrease.

A well-recognized issue coming along with large audiences is passivity among students. This is often seen as one of the biggest problems in learning arrangements (Renkl, 1996). With increasing group size social barriers are raised that make members standing out of the group feel uncomfortable, e.g., when asking a question or commenting on the discourse. Students may consider themselves as being perceived to be incompetent in case they would frankly utter comprehension problems. As a consequence, students feeling overchallenged typically expose a passive behavior (Schworm and Fischer, 2006). The cause of such misjudgments is often that students are isolated from each other and have few possibilities to sense relevant, and often similar, impressions of other students. They might, e.g., miss to recognize that they are not alone in having comprehension problems. Computer-mediated communication by so-called dig ital backchannels can help listeners to share their impressions and engage in collaborative activities, without interrupting the lecture. In order to not only strengthen, but also to increase awareness of ongoing group dynamics, both sophisticated social interactions and group communication are necessary. 
Since a decade or so, dig ital backchannels have been spontaneously used in - mostly IT and Computer Science - professional conferences with large audiences to great success. At the beginning of the decade, one of the authors of this paper has experienced the use of an IRC ${ }^{1}$-based digital backchannel at a twice-yearly meeting of the W3C: The backchannel enabled an audience of between six and eight hundred to quickly agree on objections to a speaker's statement and to choose a few audience members to wave the flag. At some Computer Science conferences, like multimedia or Semantic Web conferences, Twitter has become a commonly used tool for commenting presentations, thus raising the audience's awareness to salient, or questionable, paper presentations. Such a use of a general purpose digital backchannel is not unproblemat ic, though. In her blog post "spectacle at Web2.0 Expo... from my perspective" 2 of November 24, 2009 danah boyd reports on how, during a talk she gave, she lost the contact to her audience which increasingly moved from the frontchannel of the talk to backchannels beyond her reach. Admittedly, part of the problem was that the backchannels used by the audience de facto excluded the speaker.

This article reports on the conception of the digital backchannel Backstage dedicated to large classes aiming at empowering not only the audience but also the speaker, at promoting the awareness of both audience and speaker, and at promoting an active participation of students in the lecture.

The contributions of the article are as follows:

- The description of a modus operandi for a use of a digital backchannel in large classes

- The functionalities needed for a dig ital backchannel to support this modus operandi

- The scientific underpinning of the approach with findings and theories of learning sciences

The research reported about in this article is a joint work between computer and learning scientists.

\section{THE B ACKCHANNEL'S MODUS OPERANDI}

Like every Monday morning, Sue Byrd is giving the freshmen's lecture on Linear Algebra for an audience of 280 students. She feels better becau se the backchannel is on and the students begin to be used to it. A reminder would not harm, though: "If at some point you get lost, post it on the backchannel", Sue says, "And refrain from messages on yesterday evening's soccer." When it comes to the Laplace formula for computing the determinant of an n-by-n matrix, there is a rush of students' messages. Sue sees that many are posting messages and therefore awaits a few seconds for the backchannel to inform her: "What is a matrix' signature?" was asked by 37\%. She recalls the concept needed for understanding Laplace formula and goes ahead with her explanation. Meanwhile, Bob is engaged in a private chat on the backchannel with Ann: "I thought the formula was called Leibniz formula. Is Dr Byrd confusing names?" Ann finds the remark interesting and suggests to Bob to make it public. He does so and within five minutes more than $20 \%$ of the lecture's audience support the question, leading the backchannel to forward it to Sue who mentions that there are two distinct formulas for determinants of nby-n matrices. At the same time, Charly asks on the backchannel "Recall the formula for the det of $2 \times 2$ matrix". Ann, who often tends to be rather direct, posts a public answer: "Dr Sue explained it last week but you were once again skiing". This sharp answer gets support, Charly's question is turned down by $80 \%$ of the students and therefore not forwarded to the lecturer. After the lecture, Sue has a look at the backchannel's anonymized log: She is satisfied that the communication have been limited to 18 of the 90 minutes of the lecture and to three issues - among others yesterday's victory of the FC Bayern. She notices that the number of students more interested in FC Bayern's victory than in determinants fits well with that of student who did not made their last week's home work.

This admittedly simplified and idealized scenario stresses the following points:

1 Internet Relay Chat

2 http://www.zephoria.org/thoughts/archives/2009/11/24/spectacle_at_we.html++ 
- Even though it is preferable that students immediately ask questions when they do not recall a concept, in a large class lecture this is meaningful only if the question is relevant to sufficiently large a nu mber of students.

- Side remarks to neighbors might be relevant to the whole audience and worth forwarding to the lecturer. Deciding whether this is the case should be a social decision.

- Knowing what students thought, or did, during a lecture is of considerable help for a lecturer.

The next section elaborates on the backchannel's functionalities outlined in the above scenario.

\section{PROMOTING AWARENESS AND PARTICIPATION AMONG STUDENTS}

Yardi (2008) suggests that strengthening the collective consciousness of, and empowering, large lecture audiences by an appropriately designed digital backchannel is possible. Appropriate forms of communication and feedback may support students engaging in collaborative group discussions - or more specifically, fast information exchange-and actively participating in the lecture discourse. The importance of active participation is also highlighted by practitioners such as Arthur F. Thurnau awarded Professor of Education at Michigan University, Deborah Loewenberg Ball, who states that "Students' opportunities for learning are reduced when their role is mainly that of spectators in large lecture classes" comprise asking and answering of questions or engaging in controversial discussions. Though, currently, extensive group work is hardly possible in large lectures, well selected collaborative activities could reduce negative effects of large class lectures. One reason is that with those collaborative activities "inadequate reasoning will be exposed, [...] and higher quality understanding will emerge" (Slavin, 1996, p. 49). In the following, the forms of communication on the backchannel is described that may foster lecture rs' and students' awareness of group dynamics, that embraces empowerment of students and calls for active participation.

\subsection{Short Messages}

In academic conferences computer-mediated communication software has been leveraged as digital backchannels (e.g., McCarthy and boyd, 2005; Saunders et al., 2009). With digital backchannels students can engage in group discussions during presentations without disrupting the lecturer's discourse. Due to their success, recent efforts in e-learning have been focused on the application of digital backchannels in higher education (e.g., Costa et al., 2009; Yardi, 2008).

Though, primarily, user-driven trends have made microblogs the privileged media for digital backchannels (McNely, 2009), microblogs fulfill the requirements imposed by learning settings. They provide informal group communication within the classroom appropriate to post work-related information, to get aware of other's impressions and to build common-ground (Zhao and Rosson, 2009). The brevity of microblog messages (typically less than 200 characters) make students write their contributions in a concise manner-one piece of information per message. This makes contributions written and read more quickly. The fact that students write their questions or argumentations, instead of talking about them, is giving them more time to reflect about the discourse. This could lead to a deeper understanding of arguments posted by others (e.g., Kuhn and Goh, 2005). Concise messages could support students in dealing with the backchannel discourse more intensely. Thus, compared to other backchannel media, like IRCs, microblogs can help to keep students' distraction at a lower level. Being persistent, backchannel conversations can furthermore be reviewed and rearranged specifically for reworking a lecture. We believe that the possibility to benefit from collaboratively created lecture notes increases students' incentives to partake. Since microblogs are easy to use, following the principle of the least surprise, special training is often unnecessary.

Many microblogs like Twitter allow the use of a free and unbounded vocabulary for tags, so-called hashtags that are extracted from messages and displayed in a tag cloud. Messages can be sorted out, or retrieved, using tags. Tag clouds give an insight into the tagging vocabulary. During lectures, however, the usefulness of free tagging vocabulary is doubtful. Since finding useful tags is a non-trivial task, e.g. avoiding

3 http://www.crlt.umich.edu/faculty/Thurnau/Prof_Ball_Su mmary.pdf 
synonyms and being aware of case sensitivity, it can contribute to students' distraction and be subject to abuse. Thus, experimental evaluations need be carried out for determining which form of tagging vocabularies can be useful on the backchannel. In the following, we describe a limited form of tagging with predefined and very small vocabularies.

\subsection{Modes of Communication}

The conception of a digital backchannel for large lectures we developed includes public, private as well as anonymous and pseudonymous forms of inter-personal communication which are specified by the user within the message. Public communication is visible to the entire audience and likely to be the standard form of communication within a lecture class. Private communication allows a student to share opinions and ideas with others in confidence and to achieve social support: the other students can encourage her to make her contributions public. Thus, private communication can be a stepping stone to public communication. Public messages may, but do not need to, refer to other students using the @-prefix of IRCs and Twitter (Figure 1 and Figure 2). Private communication is only visible to students that are specified by the author of the message (Figure 3). We therefore introduce the @>-prefix in the developed backchannel. Referring to the scenario described in Section 2, Ann's public message to Charly and Bob's private backchannel message to Ann is given in the Figure 2 and 3. Additionally, Backstage can be customized to allow students to post messages anonymously, by using the symbols *** (Figure 4). Research indicates that not showing the author of a message could lower the barrier to participate in backchannel conversations. It can hardly be stated a priori which forms of communication are preferable for a given lecture, since experimental findings are inconclusive (Er and $\mathrm{Ng}, 1995$ ). Thus, the lecturer, possibly in agreement with her audience, should be able to customize the communication to fit the requirements at hand.

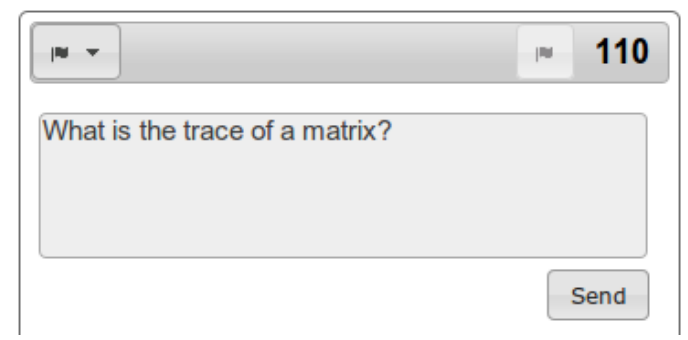

Figure 1: Editor window with a public message, visible to all.

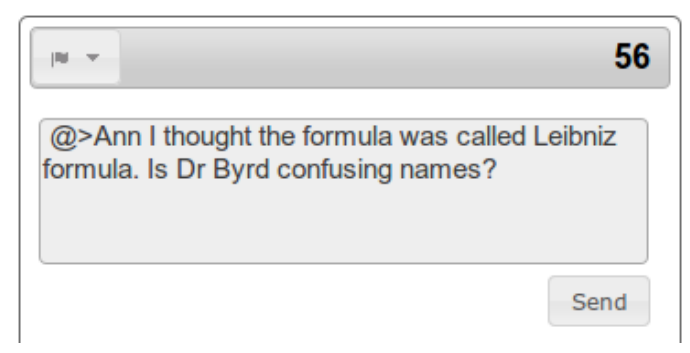

Figure 3: Editor window with a private message to Ann, only visible to her and the sender. Note the first symbols: @>

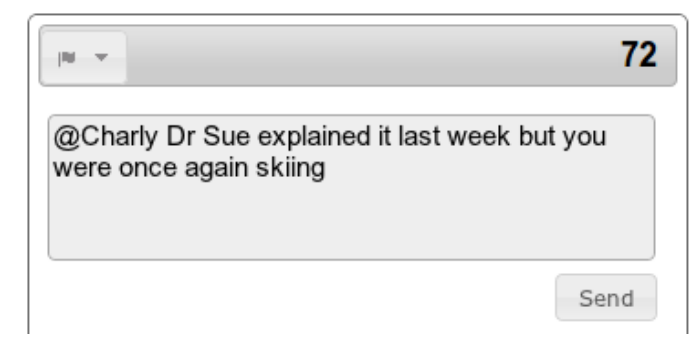

Figure 2: Editor window with a public message to Charly, visible to all. Note the first symbol: @

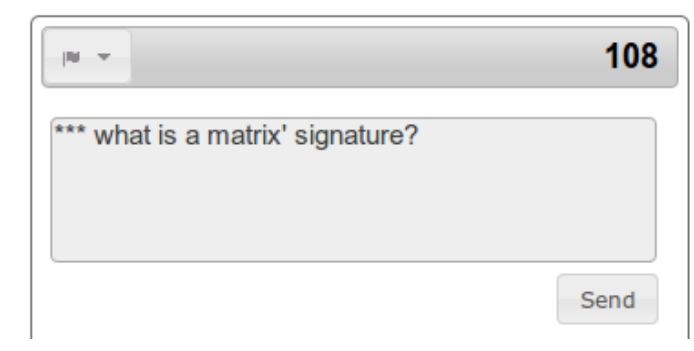

Figure 4: Editor window with an anonymous message, visible to all. The author of the message is not shown. Note the first sy mbols: $* * *$ 


\subsection{Collective Message Rating and Annotations}

Students can approve or reject messages by means of a concise rating scheme: A positive rating expresses approval and a negative rating expresses rejection. By aggregating these ratings a top-k ranking of messages can be determined that reflects the relevance of messages as considered by the audience. Such a top-k ranking of messages provides the lecturer with a very concise content-related collective appraisal of the relevant backchannel communication. Regarding the top-k messages lecturers can keep additional explanations short or present them in more detail if the audience indicates interest or problems.

We believe that not only a relevant message but also messages that refer to, or are referred to by that message, might be of interest to the lecturer. For example if an answer is considered highly relevant the corresponding question should be likewise considered relevant. We intend to achieve this by adaptations of eigenvector-based ranking algorithms like, e.g. HITS (Kleinberg, 1998) or the more involved PEST (Weiand et al., 2010).

To resemble the natural decline of relevance induced by the progress of the lecture discourse, ranking of messages should be subject to aging. Aging causes messages to climb down the ranking over time, unless students continue to rate them (Figure 5).

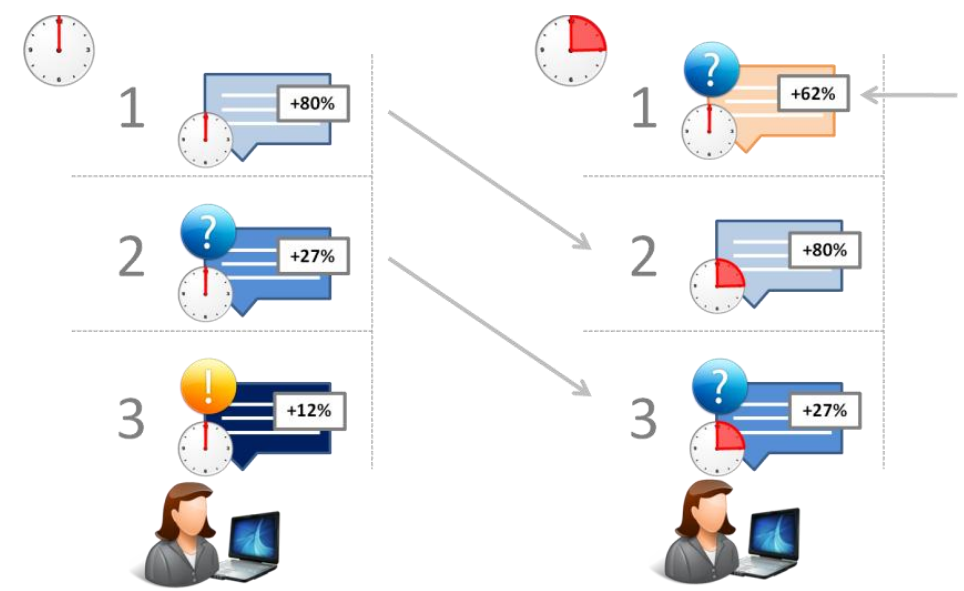

Figure 5: Aging makes messages climb down the ranking over time (indicated by the two clocks at the top and the arrows at the center), such that a more recent message may replace an older, though better rated, one (see the message at the top in the right column; the percentages indicate the aggregated rating values for a message).

Besides, aging serves two additional purposes. First, students' interactions necessary for estimating the relevance of a message are reduced. Second, aging makes the ranking robust against varying backchannel activity. Otherwise, messages that are rated highly positively in peaks of backchannel activity would not be turned down and hence congest the ranking. We intend to investigate in experimental evaluations which aging formula should be used. Ratings of messages also allow for the determination of intra-community status of their respective authors. The more positive ratings the messages of a student receive, the more intracommunity status the student gains (Figure 6). 


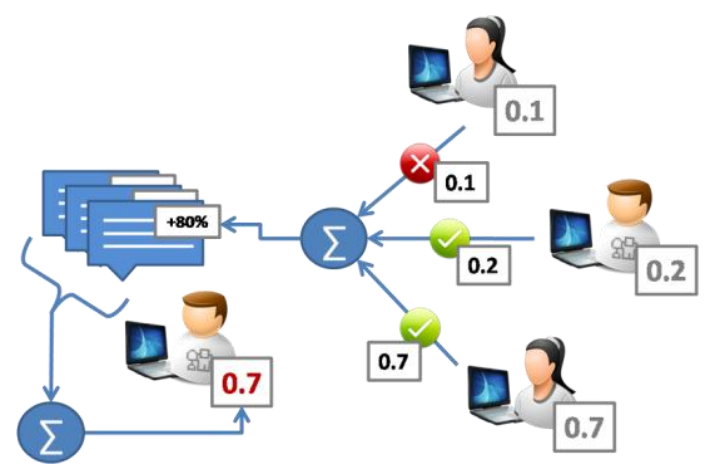

Figure 6: Intra-community status of a student can be determined by the ratings of her messages. The rating of a student, in turn, can be weighted with her intra-community status (the green check-marks illustrate approval, the red cross-marks rejection).

In turn, intra-community status can be used as a weight that is put on the student's backchannel interactions. Students lose ground if the large part of the audience continuously rejects their contributions, but gain influence when their contributions are mostly approved. Thus, intra-community status gives students feedback on the value of their contributions and can be an incentive to partake. The Figure 7 shows how students can rate a backchannel message on Backstage.

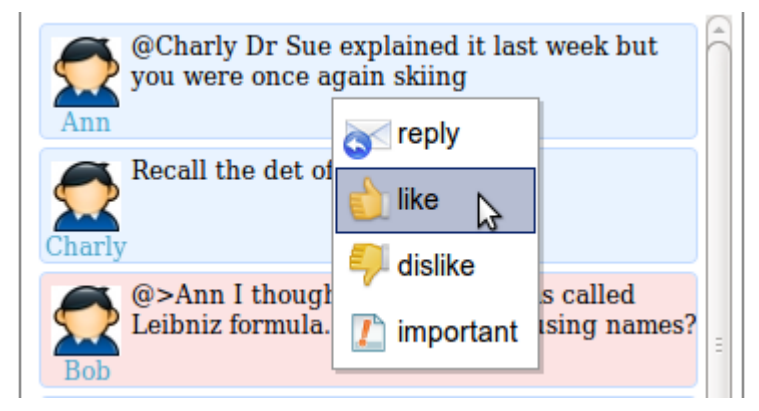

Figure 7: By right-clicking at a message in the timeline the corresponding context menu for the message is shown. Using the context menu the user can reply to, rate (like or dislike), or annotate the message with further keywords (e.g. important). The lecturer predefines the annotations that should be available.

Apart from rating, on Backstage messages may also be annotated, e.g., as irrelevant messages. Therefore, a very limited keyword vocabulary for this kind of tagging is predefined by the lecturer during the customization of Backstage. Additionally, annotations can also be automatically determined. For example, the system could determine off-topic messages (e.g., specified by a database query) and annotate them accordingly.

Messages can be given more than one annotation. The annotations can be aggregated, thus yielding a degree for each keyword. Similar to rating a backchannel message, intra-community status may be involved in the aggregation. Both annotations and rating allow for fine-grained feedback to the lecturer. For example, the message "Publishing board drawings online would save us time" could be rated highly positively but may likewise be annotated as irrelevant with respect to the lecture. Especially, this example highlights interesting dependencies between ratings and annotations: Messages that are annotated as irrelevant by a sufficient number of students can be safely ignored, or only weakly considered, in the ranking of backchannel messages. Therefore, it needs to be specified which and how annotations influence the message ranking.

One issue of rating based collaborative filtering is the so-called First-Rater-Problem (Melville et al., 2002): A message cannot be recommended to the lecturer, or other users, unless some user has previously rated the message. Hence, when the students are reluctant to rate, Backstage cannot provide the lecturer with a top-k ranking. As a remedy, it has been suggested to combine collaborative filtering with content-based filtering. We believe that for Backstage there are interesting variants of such hybrid filtering approaches conceivable, especially when keeping the interplay between the user-centric rating and the content-centric collective feedback to the lecturer in mind. 


\subsection{Collective Feedback to the Lecturer}

Backchannel communication can be distinguished into process-oriented and content-oriented communication, among others. Process -oriented communication deals with the analys is and steering of the frontchannel discourse, e.g., pace of lecturing. Content-oriented communication deals with the public frontchannel and backchannel discourse, e.g., critics or appraisal (Cogdill and Kilborn, 2001). Both kinds of communication may contain relevant feedback for lecturers during their discourses. However, this would involve comprehending the backchannel discourse while lecturing, a task that is often infeasible. To give lecturers quickly comprehensible and concise feedback during lecturing makes aggregation. Suppose that collective feedback on the lecturing pace is sought for. The lecturer customizes the backchannel with a field "pace" and two notifications, "too slow" and "too fast". During the lecture students can notify the lecturer regarding her lecturing pace. These notifications are aggregated and graphically displayed at the lecturer's dashboard very concisely to give the lecturer the possibility to quickly grasp the audience's feedback and react on it.

In order to avoid giving unconsidered feedback to the lecturer, students explain their feedback in a backchannel message. As mere messages, other students can rate and annotate them. These ratings can further be considered in the aggregation of the feedback (Figure 8).

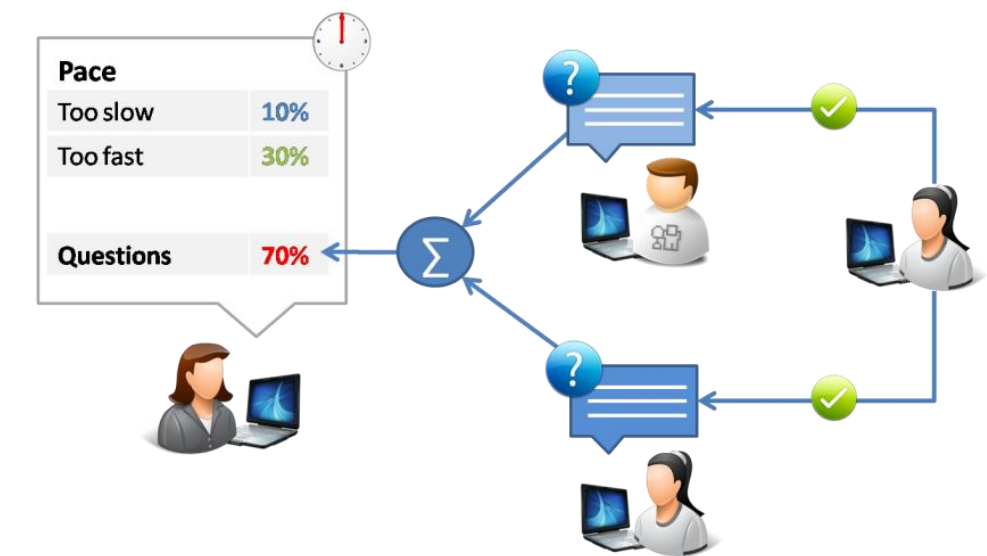

Figure 8: This figure shows two messages that were annotated with "Question". A student approves the two messages. These messages, together with their ratings, slip in the lecturer's aggregated overview of the backchannel, that may underly aging.

The Figure 9 to Figure 12 show the way collective feedback to the lecturer is currently given on Backstage. It has been shown that assistance in how to give feedback and comments, among other things, is necessary, (e.g., Stegmann et al., 2007). Thus, it could be helpful to add further instructions to Backstage as described in Section 4. Similar to the relevance ranking of messages, aggregated feedback to the lecturer underlies aging, in order to rese mble the progress of the lecture discourse. Depending on the customization of the backchannel, the impact of students' feedback to the lecturer can be weighted with their intra-commun ity status. That is, feedback of students with high intra-community status is considered more important than that of students with low intra-community status. Arguably, whether to use egalitarian or status-weighted aggregation depends on various factors, for example, the type of feedback and the constitution of the audience. Further research regarding this topic is necessary. 


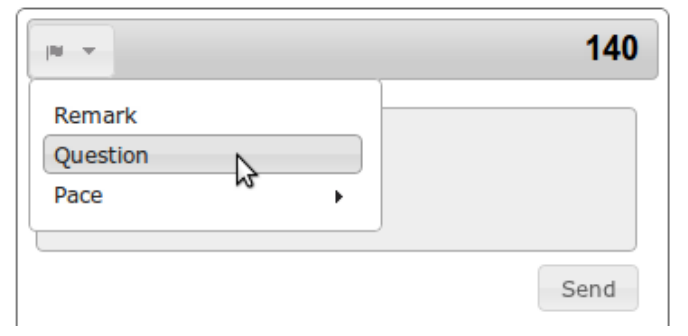

Figure 9: As a feedback that is aggregated and displayed on the lecturer's dashboard the user selects the category Question.

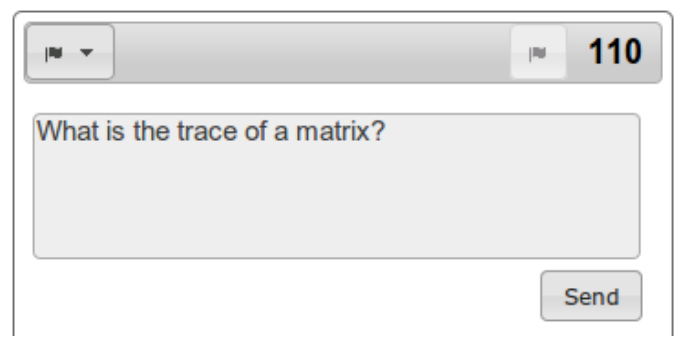

Figure 10: After selecting the category of the feedback (note the flag-icon near the top right corner) the user writes a message providing additional information for the feedback.

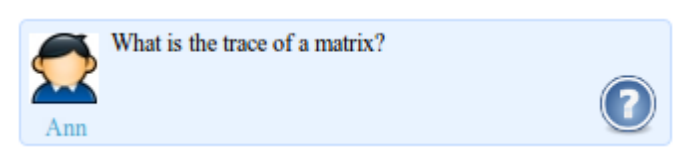

Figure 11: The public message and its annotation are visible to all. Thus, users may rate the message. The ratings may be considered in the aggregation of the collective feedback to the lecturer.

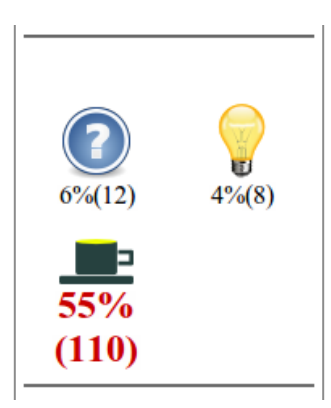

Figure 12: At the lecturer's dashboard the aggregated number of messages annotated with Question, Remark and Off-Topic, among others, are displayed.

\subsection{Performance Feedback to the Students}

Beside the lecturer, also students may obtain feedback by data that is acquired both during and after a lecture. In addition to the data of their backchannel comments, students are as sessed in short surveys to gain information regarding their current knowledge, motivation and progress. Giving a student an overview on the data can contribute to her reflections and learning (e.g., Hattie and Timperley, 2007). Topic-related knowledge can be tested by short quizzes consisting of questions and sets of possible answers. When such a quiz is opened by the lecturer, students choose from the possible answers for a specified amount of time (Figure 13). This can be combined with discussions on the backchannel. When the specified time runs out the lecturer closes the quiz. The aggregated result is then displayed at the student's and the lecturer's dashboards (Figure 13). On the basis of these results, further backchannel or frontchannel discourse can emerge. Not only do quizzes allow students and lecturers to get an overview of the individual and collective learning performance, but also does it break up the lecture discourse. In his review on the effects of large classes, Cuseo (2007) remarks that students' attention and concentration drastically declines after ten to twenty minutes of continuous lecturing. Additional to multiple choice quizzes which usually comprise answers that are either correct or incorrect, further quizzes with different kinds of students' responses are conceivable. For example, quizzes may as sess the students' opinions or ask for keywords best describing the subject at hand.

After lectures, students may fill out session-related surveys that poll interest, individual impressions regarding the lecture, and the perceived usefulness of the backchannel discourse. Also, the data retrieved from these surveys are processed and displayed on the dashboards. Moreover, the data are also relevant datasets for experimental evaluations. 


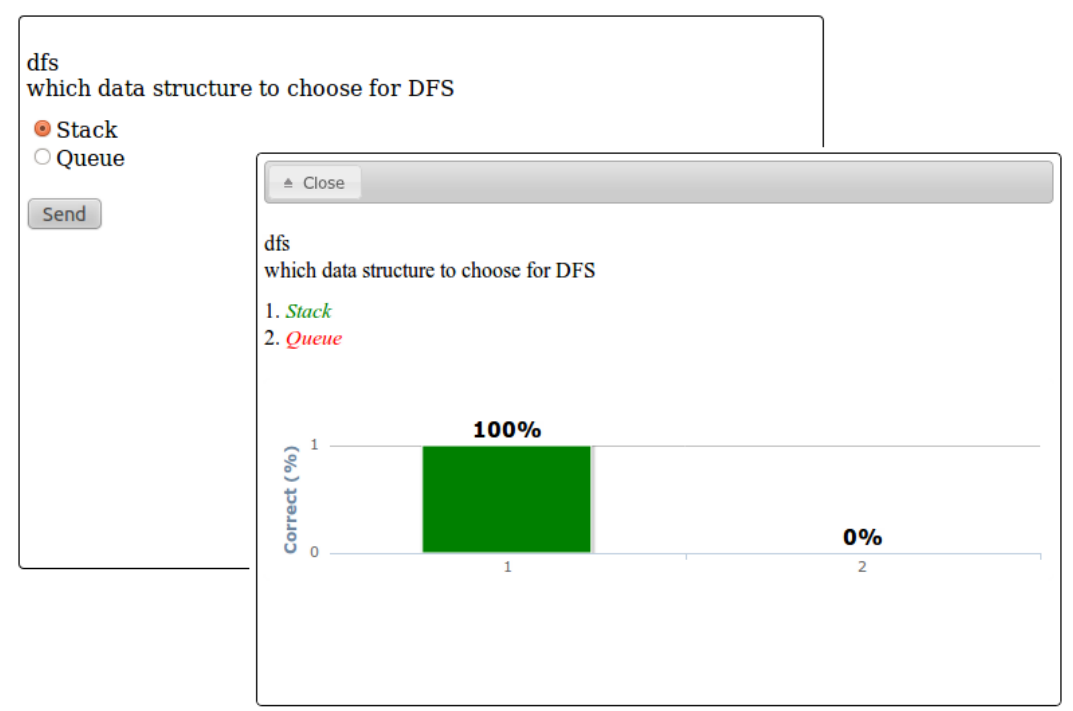

Figure 13: (Back) The student's view of the quiz is shown after the lecturer has opened the quiz. (Front) The lecturers view of the quiz' aggregated results is shown after the lecturer has stopped the voting. The correct answer and the bar indicating the number of students who have chosen the corresponding answer is highlighted in green. The incorrect answers (and the respective bars) are highlighted in red.

\section{BACKCHANNEL'S DEPLOYMENT AND EVALUATION}

One issue that might arise with such a highly customizable digital backchannel is to find the appropriate fine-tuning to fit the lecture setting at hand. Though the realization of Backstage is focused on easy customization, the approach needs to be thoroughly tested. Also, Backstage is to be deployed into real lecture settings in order to evaluate its effectiveness for students' learning. These evaluations are done on the bas is of data that are collected on Backstage as well as on the students' knowledge gain. It is difficult to determine whether the benefits of using Backstage for learning as described above results in an improvement of students' grades. Yet, we argue that an improvement of students' grades might be too restricted an indicator for learning success. The availability of the digital backchannel to students can contribute to a more enjoyable and active learning environment and thus supports learning on a more mediate level. We intend to provide a thorough discussion of this topic in the near future.

As a new technology, lecturers and students need to be guided in how to use the backchannel. Especia lly, more fine-grained guidance is necessary on how students communicate on the backchannel. Studies suggest that many students have difficulties in correctly formulating questions or argumentations. Moreover, findings show that students create arguments and counterarguments on a rather superficial way (e.g., King, 2002) or do not take the arguments of others into account (Stegmann et al., 2007). One way to overcome these problems is to give students concise instructions on tasks like asking questions or formulating arguments (e.g., King, 1997; Stegmann et al., 2007; Weinberger et al., 2010). This can be accomplished by using socalled scripts which have been shown to be effective (e.g., Steg mann et al., 2007; O'Donnell and Dansereau, 1992; Weinberger et al., 2010). Especially when dealing with novices, learning in digital environments should be guided (Kollar et al., 2007). When becoming more advanced backchannel users, these scripts may gradually be faded out (Wecker and Fischer, 2007). The fading of scripts can be supported by data that is collected on Backstage (cf. Section 3.5) and thus allows for the adaption of scripts to the student's individual needs. It is reasonable to include various kinds of scripts into Backstage to support students when this seems necessary. Also, this kind of support could be helpful, based on the findings of Aleven and colleagues (2003), since they found out that students are often not aware of needing help. 


\section{RELATED WORK}

Harry and colleagues (2009) present a special purpose backchannel that supports Question-and-Answer sessions after conference presentations. During a presentation listeners can post their questions on the backchannel that can be rated by other listeners to either approve their relevance or to reject them. According to ratings a ranking of the eight most positively rated messages are determined and projected on the wall. The panelist may select the best rated questions to answer and tally them on the backchannel. Questions previously posted and tallied cannot be posted again. The rating scheme, though comprehensible, considers aging of messages and the activity of the audience. That is, in the ranking highly ranked old messages may be replaced by less highly ranked but recent messages. The article presents empirical findings on the use of the backchannel in various, mainly industrial conferences. The article also describes experiences made with the backchannel during those conferences.

The backchannel only allows directed communication from the audience to the panelist. Thus, collaborative activities are only marginally supported. This is also highlighted in the paper: Listeners complained about the missing possibility to reply to other listeners. The backchannel does not pro vide intracommunity status and, thus, the backchannel interactions are egalitarian. While this may be reasonable in presentations with short-existing audiences, in lectures with long-existing audiences intra-community status may be worthwhile.

Ebner (2009) has investigated how presentations can be improved by microblogging channels. The experiment was conducted at the E-MEDIA 2008 conference using Twitter as the microblogging platform. During presentations the Twitter timeline was projected on the wall via a separate projector. This made it possible for the audience to follow both presentation and the backchannel discourse on Twitter at the same time. Mainly, the backchannel was used to share links as a supplement of the presentation, to comment on the presentation, i.e. reacting on the statements of the speaker, as well as on the quality of the slides. The article highlights Twitter as a way to persist both the presentations as well as the discussions on the microblogging platform. On the basis of their findings, the authors conclude that the use of microblogs improves learnerlecture interactions in large classrooms, since it may provide solutions to major problems in learn ing settings: Feedback lag (students hesitate to give feedback), Students' apprehens ion (students fear to ask) and the Single-Speaker Paradig m (the fact that only one person speaks leads to less activity).

The approach described in Ebner (2009) focuses on the mere group communication by using the gen eral purpose mic roblogging platform Twitter. While general purpose microblogging platforms have proven to be useful in daily life they lack several aspects that we believe to be important in learning settings. Although they may enhance collaboration by group communication, they usually do not take the outstanding role of the lecturer into account: They do not provide means of immediate feedback to the lecturer, and neither do they provide the possibility to socially agree on relevant content - all messages are considered equally important. This makes it often difficult for lecturers to get aware of the relevant thoughts and impressions of the audience.

The concept of the aforementioned quizzes are reminiscent to Audience Response Systems (ARSs) that have already shown to be effective for learning purposes in various ways (Kay and LeSage, 2009). ARSs basically allow usually co-located audience members to interactively engage in polls during presentations. In several studies, lecturers reported that students appreciate ARSs and that participation of students is increased. Students reported that they are more interested and engaged in the learning discourse when Audience Response Systems are used. Hence, similar to ARSs, quizzes may help to increase students' attention, participation and engagement.

\section{CONCLUSION}

This paper presents the modus operandi and functionalities of a digital backchannel that increases awareness of both lecturer and students in large class lectures. It embraces the empowerment of students while rewarding the lecturer with instant feedback giving an insight into the dynamics of the audience. Important aspects of the modus operandi are motivated by findings from learning sciences.

The project reported about in this paper is currently redesigned to account for the integration of presentation slides which, as an additional operation mode of Backstage, can be published on the dashboards. Since the integration of slides allows for a better structuring of the backchannel communication and further 
collaborative interactions of students, the redesign affects the large part of the user interface and workflows. The extended version of Backstage is presented in a companion paper in the near future. In Fall 2011 we intend to thoroughly test Backstage in a field study jointly with educational scientists.

During a first phase from the Fall of 2009 up till the Spring of 2010, the design of Backstage as reported about in this paper has been worked out in a joint work of computer and learning scientists. The second phase, from Spring to Fall 2010 was devoted to implementing Backstage relying as much as possible on standard web technologies.

\section{REFERENCES}

Aleven, V., Stahl, E., Schworm, S., Fischer, F., and Wallace, R., 2003. Help seeking in interactive learning environments. Review of Educational Research, Vol. 73, No. 3, pp. 277-320.

Bry, F., Gehlen-Baum, V., and Pohl, A., 2011. Promoting Awareness and Participation in Large Class Lectures-The Digital B ackchannel B ackstage. In Proceedings of the IADIS Int. Conf. e-society, Avila, Spain, pp. 27-34.

Cogdill, S., and Kilborn, J., 2001. Backchannel: Whispering in digital conversation. In Proc. of the 34th Hawaii International Conference on System Sciences (HICSS), IEEE Press.

Costa, C., Beham, G., Reinhardt, W., and Sillaots, M., 2009. Microblogging In Technology Enhanced Learning: A UseCase Inspection of PPE Summer School. Workshop at the European Conference on Technology Enhanced Learning (ECTEL), Maastricht, The Netherlands.

Cuseo, J., 2007. The empirical case against large class size: adverse effects on the teaching, learning, and retention of first-y ear students. Journal of Faculty Development, Vol. 21, pp. 5-21.

Ebner, M., 2009. Introducing Live Microblogging: How single presentations can be enhanced by the mass. Journal of Research in Innovative Teaching, Vol. 2, No. 1, pp. 108-111.

Er, M. C., and Ng, A. C., 1995. The anonymity and proximity factors in group decision support systems. Decision Support Systems, Vol. 14, Issue 1, pp. 75-83.

Harry, D., Gutierrez, D., Green, J., and Donath, J., 2008. Backchan.nl: integrating backchannels with physical space. In Extended Abstracts on Human Factors in Computing Systems (CHI); ACM, Florence, Italy, pp. 2751-2756.

Hartmann, M., 2007. Eliten und Macht in Europa - ein internationaler Vergleich [Elites and Power in Europe - an International Comparison]. Campus Verlag, Frankfurt am Main.

Hattie, J., and Timperley, H., 2007. The Power of Feedback. Review of Educational Research, Vol. 77, No. 1, pp. 81-112.

Kay, R. H., and LeSage, A., 2009. A. Examining the benefits and challenges of using audience response systems: A review of the literature, Computers \& Education, Vol. 53, pp. 819-82.

King, A., 1997. ASK to THINK-TEL WHY: A model of transactive peer tutoring for scaffolding higher level complex learning. Educational Psychologist, Vol. 32, No. 4, pp. 221-235.

King, A., 2002. Structuring peer interaction to promote high-level cognitive processing. Theory into Practice, Vol. 41, No. 1, pp. 33-39.

Kleinberg, J., 1998. Authoritative sources in a hyperlinked environment. Journal of the ACM, Vol. 46, No. 5, pp. 604632.

Kollar, I., Fischer, F., and Slotta, J. D., 2007. Internal and external scripts in computer-supported collaborative inquiry learning. Learning and Instruction, Vol. 17, pp. 708-721.

Kuhn, D., and Goh, W. W. L., 2005. Arguing on the computer. In T. Koschmann, D. Suthers \& T. W. Chan (Eds.). Computer Supported Collaborative Learning 2005: The Next 10 Years! In Proceedings of the International Conference on Computer Supported Collaborative Learning. Lawrence Erlbaum Associates, Mahwah, NJ, pp. 125134 .

McCarthy J., and boyd d., 2005. Digital backchannels in shared physical spaces: experiences at an academic conference. In Extended Abstracts, Human Factors in Computing Systems (CHI); ACM, Portland, USA, pp. 550-553.

McNely, B., 2009, Backchannel Persistence and Collaborative Meaning-Making. In Proceedings of the 27th ACM International Conference on Design of communication (SIGDOC), New York, USA, pp. 297-304.

Melville, P., Mooney, R., and Nagarajan, R., 2002. Content-Boosted Collaborative Filtering for Improved Recommendations. In Proceedings of the 18th National Conference on Artificial Intelligence (AAAI), Edmonton, Canada, pp. 187-192.

O'Donnell, A. M., and Dansereau, D. F., 1992. Scripted cooperation in student dyads: A method for analyzing and enhancing academic learning and performance. In R. Herz-Lazarowitz, and N. Miller (Eds.). Interaction in cooperative groups: The theoretical anatomy of group learning. Cambrid ge University Press, pp. 120-141. 
Renkl, A., 1996. Träges Wissen: Wenn Erlerntes nicht genutzt wird [Inert knowledge: when what is learned is not used]. Psychologische Rundschau [Review of Psychology], Vol. 47, pp. 62-78.

Saunders, N., Beitrao, P., Jensen, L., Jurczak, D., Krause, R., Kuhn, M., and Wu, S., 2009. Microblogging the ISMB: A new approach to conference reporting, PloS Computational Biology, Vol. 5, No. 1.

Schworm, S., and Fischer, F., 2006. Academic help seeking. In H. Mandl, and H. F. Friedrich (Eds.). Handbuch Lernstrategien [Handbook of Learning Strategies]. Hogrefe Verlag, Göttingen.

Slavin, R. E., 1996. Research for the future - Research on cooperative learning and achievement: What we know, what we need to know. Contemporary Educational Psychology, Vol. 21, pp. 43-69.

Stegmann, K., Weinberger, A., and Fischer, F., 2007. Facilitating argu mentative knowled ge construction with computersupported collaboration scripts. International Journal of Computer-Supported Collaborative Learning, Vol. 2, No. 4, pp. 421-447.

Wecker, C., and Fischer, F., 2007. Fading scripts in computer-supported collaborative learning: The role of distributed monitoring. In Proceedings of the 8th Conference on Computer-Supported Collaborative Learning (CSCL), New Jersey, USA.

Weiand, K., Kneiß1, F., Furche, T., and Bry, F., 2010. Term-Propagation over Wiki Structures as Eigenvector Computation. In Proceedings of 5th Semantic Wiki Workshop (SemWiki), Heraklion, Greece.

Weinberger, A., Stegmann, K., Fischer, F., 2010. Learning to argue online: Scripted groups surpass individuals (unscripted groups do not). Computer in Human Behavior, Vol. 24, No. 4, pp. 506-515.

Yardi, S., 2008. Whispers in the classroom. Digital Youth, Innovation, and the Unexpected. MIT Press, Cambridge, pp. 143-164.

Zhao, D., and Rosson, M., 2008. How might microblogs support collaborative work?. Workshop on Social Networking in Organizations. San Diego, USA. 